\title{
El imposible testimonio: Celan en Derrida*
}

\author{
The imposible testimony: Celan in Derrida
}

\section{0 impossivel testemunho: Celan em Derrida}

Ricardo Forster**

\section{Resumen}

El presente escrito quiere poner de presente algunos problemas referentes al testimonio: la veracidad del testimonio, la comparación del conocimiento metódico y científico (que exige pruebas) y el conocimiento del testimonio (que no tiene pruebas y se basa en una apuesta por la fe y juramento de lo que se testimonia), la imposibilidad de representar lo irrepresentable después de Auschwitz y la apuesta por mantener la memoria a pesar de la incapacidad que existe para representar lo ocurrido en los campos de concentración. Estos problemas van a ser tratados por medio de la poesía de Celan, quien habla y da

* El presente articulo hace parte de las investigaciones que el profesor Forster realiza sobre el pensamiento contemporáneo, la filosofía crítica y la historia de las ideas.

* Es investigador de la Facultad de Ciencias Sociales de la Universidad de Buenos Aires y de la Facultad Libre de Rosario. Doctor en Filosofia por la Universidad Nacional de Córdoba; profesor e investigador en historia de las ideas en la Universidad de Buenos Aires; ha sido profesor invitado en universidades de Estados Unidos, España, México, Israel, Brasil, República Checa, Alemania, Uruguay y Chile. Es autor de numerosos libros entre los cuales destacamos Walter Benjamin y el problema del mal (2001), Notas sobre la barbarie y la esperanza (2006), Walter Benjamin. Una introducción (2009) y La muerte del héroe (2011). 
su testimonio con motivos de preservar la memoria, sin pretensiones de verdad y de representar lo irrepresentable, en contra del olvido y las representaciones artísticas sin límites; y por medio de la apuesta de Derrida porque nadie puede testimoniar por otro.

Palabras clave: testimonio, testigo, conocimiento científico, certeza, verdad, Celan, Derrida, memoria, lo irrepresentable.

\section{Abstract}

This article wants to present some problems related to the testimony: the truthfulness of the testimony, the comparison of the methodic and scientific method (which require proofs) and the knowledge of testimony (that does not have proofs and is based on a bet on the faith and oath of what is testified), the impossibility of representing the irrepresentable after Auschwitz and the bet on keeping the memory in spite of the existing inability to represent what happened at concentration camps. These problems will be dealt through Celan's poetry, who speaks and gives his testimony with the purpose of preserving memory, without pretense of truth and representing the irrepresentable, against oblivion and artistic representations without limits; and through Derrida's bet because no one can testify for another.

Keywords: testimony, witness, scientific knowledge, certainty, truth, Celan, Derrida, memory, the irrepresentable.

\section{Resumo}

O presente escrito quer pôr de presente alguns problemas relacionados ao testemunho: a veracidade do testemunho, a comparação do conhecimento metódico e científico (que exige provas) e o conhecimento do testemunho (que não tem provas e é baseada num apostar pela fé e o juramento do que se testemunha), a impossibilidade de representar o irrepresentável depois de Auschwitz e o compromisso por manter a memória, ainda que há incapacidade para representar o que aconteceu nos campos de concentração. Estes problemas serão abordados através da poesia de Celan, quem fala e dá o seu testemunha com motivos de preservar a memória, sem pretensões de verdade e de representar o 
irrepresentável, em contra do esquecimento e das representações artísticas sem limites; e por meio da aposta do Derrida porque ninguém pode testemunhar por outro.

Palavras-chave: testemunho, testemunha, conhecimento científico, certeza, verdade, Celan, Derrida, memória, o irrepresentável.

En una conferencia ${ }^{1}$ que considero, desde distintas perspectivas, ejemplar y sugerente, Jacques Derrida se detiene a indagar, partiendo de la lectura de un poema de Paul Celan y particularmente de su última estrofa, la cuestión crucial del testimonio, de la palabra que pronunciada por el testigo es escuchada por un tercero o, más grave y oscuro, de aquella voz que remite a sí misma, que no puede salir a la búsqueda de ninguna garantía, cuyo estatuto es, desde el comienzo, endeble, frágil y de una extraordinaria complejidad. Cita Derrida a Celan, y desde allí inicia su interrogación: "Nadie / testimonia / por el testigo" (Niemand / zeugt für den / Zeugen):

\begin{abstract}
Pero este poema — escribe Derrida - es también intraducible en tanto puede referirse a acontecimientos de los cuales la lengua alemana habrá sido justamente un testigo privilegiado, a saber la Shoah, lo que algunos llaman Auschwitz, y todo lo que pudo destruir con el fuego y reducir a cenizas (cenizas es la primer palabra del poema) existencias en cantidad incontable, incontablemente, pero también innombrablemente, es decir incinerado, con el nombre y la memoria, hasta la posibilidad confirmada del testimonio (y, puesto que acabo de decir posibilidad confirmada del testimonio, tendremos que preguntarnos si el concepto de testimonio es compatible con algún valor de certeza, de seguridad, inclusive de conocimiento como tal (Celan).
\end{abstract}

¿Cuál es el lugar del testigo? ¿Cuáles, si los tiene, son sus privilegios? Preguntas iniciales, indicación, ya en el comienzo, de un problema mayúsculo. ¿Qué relación existe entre el testigo, su palabra y la certeza? ¿Puede abordarse el testimonio del testigo desde algún "valor de certeza, de seguridad, inclusive de conocimiento como tal"? ¿El habla del testigo es, acaso, del orden de la verdad? Y si el testigo, Paul Celan, el poeta, deja testimonio en alemán, ¿podemos, al recibirlo en una traducción, recibir

1 La conferencia de Derrida se llama "Hablar por el otro", la leyó en Buenos Aires en octubre de 1996 y se publicó en Diario de Poesía. 
su contenido esencial? ¿Hay posibilidad, se cuestiona Derrida, de dar testimonio de la Shoah por fuera de la lengua en que se manifestó, es decir, el alemán?2 ${ }^{2}$ Primeros esbozos de una indagación que se interna en un territorio de lo inascible y, más grave aún, de lo innombrable que, sin embargo, alcanza a través del poema un cierto trazo de lo decible en lo indecible:

\begin{abstract}
La ceniza destruye o amenaza con destruir hasta la posibilidad de dar testimonio de la destrucción misma. Pero quizás lleguemos a pensar que la posibilidad de esta destrucción, de esta desaparición no solo del testigo sino de la posibilidad de testimoniar es también la única condición del testimonio, su única condición de posibilidad - paradójica y aporética - como condición de su imposibilidad (Celan, 1999).
\end{abstract}

Fuera del conocimiento y de su estatuto, el testimonio de la destrucción se desplaza por aquello que ha huido de toda representación, que se ha fugado de cualquier intento

2 George Steiner también se enfrentó al dilema de la lengua alemana; quizás sus más esenciales búsquedas hayan nacido de esa interrogación desesperanzada que se detuvo a indagar sobre las consecuencias del envenenamiento del habla humana. Escuchemos su reflexión: "Es posible que la única lengua en la cual algo inteligible, algo responsable concerniente a la Shoah pueda intentar decirse, sea el alemán. Es en alemán, en la fuente misma de su genio moderno, y de sus convenciones lingüisticas, es decir en los panfletos de Lutero de los años 1540, que la erradicación, la Ausrottung, de los judios de Europa, que el acto de quemarlos vivos, son enunciados claramente; es en el llamado esencial a la identidad nacional de Alemania, en el 'llamado a la Nación alemana' de Fichte, que el odio hacia el judio recibe el aval de una filosofía abarcativa. Es en alemán que Heine, desde 1820, ha enunciado claramente la advertencia según la cual en el lugar donde algunos libros habrian de quemarse, serian quemados seres humanos. Es Nietzsche, quien, con una clarividencia casi de sonámbulo, ha identificado el antisemitismo asesino como el dinamismo que define el espíritu alemán. Son las palabras de Franz Kafka muy especialmente en La Metamorfosis y La Colonia Penitenciaria, que prevén con exactitud el vocabulario, la tecnología, la política y la psicología del subhumano, asi como fueron llevados a cabo en la situación de los campos de concentración. Es Karl Kraus que pone una fecha completa: 'Ios últimos dias de la humanidad', que da al Apocalipsis de lo inhumano su calendario. Las palabras literalmente impronunciables, que son utilizadas para planificar, prescribir, registrar, justificar la Shoah, las palabras que enuncian, deciden y dictan que quemarán niños vivos bajo los ojos de sus padres, que ahogarán lentamente ancianos, hombres y mujeres, en los excrementos, que se suprimirán millones de seres en una burocracia verborrágica del crimen, son palabras alemanas. Son palabras a las cuales el carácter fantástico y el Kitsch mortuorio de la elocuencia nazi han dado una fuerza, una importancia, que pocas otras palabras han poseido en la historia de la humanidad. En consecuencia, si tiene que haber una nueva humanización del lenguaje después de la Shoah, una restitución del lenguaje de su actitud perdida para hablar a Dios y de Dios, de hablar al hombre y del hombre en un sentido un tanto responsable, tal reparación, tal restauración, no pueden más que venir de adentro de la lengua de la muerte misma" (Steiner, 1987). Tal vez toda la poesía de Paul Celan no sea otra cosa que esa imposible restauración del lenguaje, que ese compromiso por "salvar" lo que yace perdido. 
de mostrarlo en tanto que acontecimiento cuya huella es perfectamente seguible hacia algún lugar. Sin ser testimonio de un real sustraido que puede volver a presentarse ante nosotros a través del testigo y de su palabra, tampoco es lo remitible al orden de la ficción, aquello que se vuelve cierto por los extraños vericuetos del lenguaje poético. En su suspensión, en su paradójica y aporética condición de imposibilidad, el testimonio da lugar a la confrontación con las "cenizas" de una destrucción intolerable, que el discurso no puede nombrar sin extraviarse, sin cometer injusticia, sin hablar por el otro que no ha podido ni podrá hablar. Celan, su poema, nace de esta convicción: "Nadie / testimonia / por el testigo". Derrida insiste:

Cuando el testimonio aparece confirmado y se vuelve por tanto una verdad teórica demostrable, el momento de una información o de una constancia, un procedimiento de prueba, o incluso una prueba, corre el riesgo de perder su valor o su sentido, su estatuto de testimonio. Lo cual equivale a decir - siempre la misma paradoja, la misma paradoxia, la misma matriz poéticoparadojal- que, en cuanto es confirmado, un testimonio ya no es confirmado como testimonio (Celan, 1999).

$\mathrm{Al}$ acontecer este pasaje, su confirmación como testimonio y su entrada al ámbito del conocimiento, lo que surge ya es otra cosa, su inicial andadura testimonial, que es frágil, insegura y que "no debe ser absolutamente confirmado", deja su lugar a lo verificable, a lo que puede ser incorporado al orden de la certeza, de la regla científica, de los métodos que determinarán el grado de verosimilitud que ese testimonio pronunciado por el testigo puede alcanzar. Sabemos que en los centros de investigación más reputados hoy se prefiere eludir el testimonio del testigo, porque su estatuto resulta incompatible con las rigurosidades de la episteme académica. Mientras que lo que es del orden del conocimiento exige la confirmación, aquello pronunciado por el testigo conserva, lo dijimos, su endeblez.

La palabra dubitativa del testigo no encuentra su alojamiento adecuado en las rigurosidades metodológicas de una lógica del conocimiento que transita por caminos completamente ajenos y alejados al de ese estatuto frágil e inconfirmable del testimonio. Y no solamente porque se trata, aquí como lo hace Derrida, del intento de interpretación de un poema; la voz del que estuvo allí, si alguien en verdad pudo haber estado ahí, está quebrada, pronuncia con extrema tensión algo que alcanza a aproximarnos a lo imposible de ser narrado, pero cuyo acontecer ha dejado su 
terrible marca en el testigo. En todo caso, el poeta multiplica, desde la palabra poética, la imposible univalencia de lo acontecido, de aquello que lleva el nombre de Shoah o de Auschwitz y que no alcanza ninguna palabra que pueda efectivamente decirlo. Celan en un poema inolvidable escribió:

\author{
UN ESTRUENDO: la \\ verdad misma \\ se ha presentado \\ entre los hombres \\ en pleno \\ torbellino de metáforas ${ }^{3}$.
}

Y allí quebró todo posible compromiso entre la trama metafórica de la escritura poética, su encriptada relación con el testimonio, y los mecanismos del conocimiento que reducen el campo de la verdad según las exigencias y las prescripciones de la certeza. En ese "torbellino de metáforas" vemos aparecer la infinita distancia que separa la voz titubeante del poeta-testigo, su íntima convicción de la imposibilidad de hablar por el otro, y la resolución positiva, documentada, de toda indagación científica que no puede sostenerse en esa polisemia de la verdad que se les presenta a los hombres estallada. El conocimiento necesita de la prueba, y esta se construye con documentación sólida y que no pueda contener dentro de ella ambigüedad y contradicción. El testimonio al volcarse en palabras no puede, ni quiere, deshacerse de sus propios límites y, también, de lo que al pronunciarse se vuelve sobre sí mismo sustrayéndose al mandato de quien lo pronunció. La palabra del testigo es deudora de los pasadizos secretos y oscuros de la memoria, de una memoria que al manifestarse poéticamente no hace más que dejarse atravesar por la verdad que se le presenta a "los hombres / en pleno / torbellino de metáforas".

Derrida se introduce en la traducción francesa que traslada el inicio del poema, su incipit, la palabra Aschen-Glorie, al francés Cenizas-La Gloria, para hablarnos de las cenizas de la luz, de una gloria que ha sido cubierta de cenizas; porque la

Luz (y la luz es también el conocimiento, la verdad, el sentido) no es más que cenizas, deviene cenizas, cae en cenizas como un fuego se apaga, pero ( $y$ es la

3 Este poema, como todos los que citamos, es de la edición de la obras completas de Paul Celan (1999). 
articulación móvil e inestable de este pero lo que va a importarnos) las cenizas son también de gloria, pueden ser otra vez renombradas, cantadas, bendecidas, amadas, si la gloria del re-nombre no se reduce ni al fuego ni a la luz del conocimiento. El brillo de la gloria no es solamente, o necesariamente, la luz del conocimiento y la claridad del saber (Celan, 1999)

¿Estamos quizás ante una prohibición? Así como en el Edén Yahvé les prohibió a Adán y Eva comer del árbol del conocimiento, el árbol del bien y del mal, el poeta, testigo testimoniante de lo imposible de ser dicho, no separa la palabra vuelta cenizas de aquella otra que se interna en los pasadizos del saber, de una claridad cuya luz emana del conocimiento. Desencuentro de dos lenguajes que, enfrentados supuestamente a lo mismo, dicen algo completamente distinto. El poeta, su luz de cenizas, se acerca para dejar su testimonio, incierto, frágil, inconfirmado; el investigador va hacia lo cierto y seguro, quiere solo encontrarse con aquello que no entorpezca su indagación, no puede hacer nada con las cenizas, con la voz dubitativa del testigo.

Establecer como verdad aquello innombrable es colocarlo en otra dimensión, supone trasladarse a otra lógica en la que estabilidad, certeza, verdad, prueba, constituyen fundamentos básicos, ejes desde los cuales el testimonio deberá ser leído e interpretado, tanto para aceptarlo como para desecharlo. Al volverse dato, prueba endeble, material de investigación y confrontación, la palabra testimoniante se convierte en otra cosa, pierde su estatuto y poco tiene que ver con su primera manifestación. La representación académico-científica de la ceniza destituye la presencia, en el poema, de la palabra que testimonia la destrucción de todo sentido, en el lenguaje y fuera de él. Es también lo que Derrida destaca como clave en el poema de Celan: la imposibilidad del testimonio absoluto, los límites que aparecen en la voz del testigo; pero no porque esos límites se vuelvan clausura, barrera definitiva que impide ahondar del otro lado del umbral, sino porque en esa línea demarcatoria lo que se oscurece es la luz del conocimiento, la certeza del discurso del saber.

Derrida gira hacia otro lado, nos incita a que recorramos otro camino en la distinción entre el testimonio y el conocimiento. Para hacer más explícita esta distancia resalta la presencia, en el testimonio, del juramento, en el sentido de que no hay testimonio sin algún tipo de fe jurada: 
Lo que distingue un acto de testimonio de la simple transmisión de conocimiento, de la simple información, de la simple constancia o de la mera manifestación de la verdad teórica, es que alguien se compromete a decir o a manifestar para otro, para uno o varios destinatarios, algo, una verdad, un sentido que se hizo o se hace de alguna manera presente al testigo, pero al testigo único e irreemplazable [...]; que no hay otra opción que creer o no creer, puesto que la verificación o la transformación en prueba pertenecen a un espacio extraño, heterogéneo al espacio y al momento propios del testimonio; tal es así que la experiencia del testimonio en cuanto tal supone el juramento, se sostiene en el espacio del juramento, del sacramentum, del mismo juramento que une al testigo y a sus destinatarios [...], y este juramento es sagrado, marca la aceptación de lo sagrado, el consentimiento a la entrada en un espacio santo o sagrado de la relación con el otro; hasta el perjurio implica esta sacralización del juramento (Celan, 1999).

Pasaje del testimonio a lo sagrado a través del juramento, de aquello que compromete con una dimensión trascendente; pero también señalamiento del límite infranqueable para los dispositivos de la inteligibilidad propia del conocimiento, frontera que pone fuera el fundamento que sustenta la palabra del testigo, que le da, ante el otro, su verdadera significación. La prueba queda sellada por el juramento, por este pasaje hacia lo sagrado. La representación que se construye desde el testimonio no cobra, a partir de este pasaje a lo sagrado, ninguna relación con la indagación científica o con la estetización ficcional. Es importante lo que destaca Derrida en medio de estas reflexiones sobre el testimonio, el juramento y lo santo: la singularidad irreemplazable del testigo-testimoniante, su Schwur, se vincula con el motivo indisociable: "De la muerte que nadie puede anticipar, ni ver llegar, ni dar ni recibir en lugar del otro".

Ese es el verdadero límite, lo irrebasable, lo que vuelve impúdico cualquier intento por exponer lo único intransferible, la muerte del otro, la imposibilidad de ponernos en su lugar. Derrida, siguiendo a Celan, se detiene ante este límite, expone, sin necesidad de decirlo, su absoluto reparo ante la doble tenaza que hoy aprisiona el nombre de Auschwitz: la minuciosa e infatigable representación académica y la impúdica representación de las estéticas del cine, la plástica, la música y la literatura. Poner, destacar un límite y volverlo irrebasable, marca de lo imposible de ser dicho y mostrado. El testigo no apela a las pruebas, su palabra testimoniante no necesita de ninguna 
documentación, él se instala en el juramento, en la palabra que lo compromete con lo sagrado y desde ese lugar narra lo acontecido:

\begin{abstract}
Para este testigo no hay otro testigo, no hay testigo para el testigo. Nunca hay testigo para el testigo. Es también esto lo que puede querer decir el poema de Celan. Es también esto lo que pueden seguir alegando, inversamente, todos los "revisionistas" del mundo al recusar todos los testimonios bajo pretexto de que los testimonios jamás serán, por definición, pruebas (Celan, 1999).
\end{abstract}

En un reciente artículo de Eric Hobsbawm (2000) descubrimos esta desinteligencia profunda e irreversible que separa al testigo del historiador profesional. Hobsbawm desliza la argumentación del revisionismo allí donde le otorga a la voz oscura de David Irving -un historiador instalado con los bagajes de la historiografía y sus múltiples arsenales en el campo del neonazismo y el negacionismo de la Shoah- la legitimidad de quien justifica sus dichos en pruebas documentales. El inmenso aparato de la academia está allí para respaldar la verdad científica, la única que, despejando la selva laberíntica de los testimonios incontrastables documentalmente, puede definir la veracidad de lo pronunciado. El testimonio ocupa un lugar menor, incómodo, en la vasta documentación con la que trabaja el historiador. Para él será más importante descubrir un papel firmado por Hitler o cualquiera de los jerarcas nazis, papel en el que se dice algo concreto de la "solución final", que los miles de testimonios expresados con enormes dificultades por los testigos, aquellos que solo pueden apelar al juramento, al pasaje a lo sagrado.

Para el historiador profesional se trata de vencer a los revisionistas en el terreno de la prueba, del documento, de lo constatable y verificable; se trata, en definitiva, de ejercer sobre el testimonio del sobreviviente el mismo gesto censor que el rechazo de los revisionistas que se deleitan, una y otra vez, en la imposibilidad factual del testimonio, en su radical estatuto subjetivo e inverificable. Extraña coincidencia la de un historiador inscripto en lo que podríamos denominar una tradición de izquierda y la batería argumentativa de los revisionistas y negacionistas de la Shoah ${ }^{4}$.

4 En este punto creemos necesario dejar que el propio Hobsbawm nos transmita su particular punto de vista: "Con razones óptimas, el consenso que prevalece entre los historiadores individualiza en Hitler al responsable de la 'solución final' pero la argumentación de Irving modificó la interpretación histórica del Tercer Reich. Además: Irving no niega que millones de judios perecieron entre 1941 y 1945. No niega tampoco que un gran número de judíos fue deliberadamente exterminado, y no solo víctima del cansancio, el hambre o enfermedades. Lo que hace más bien es concentrarse en sembrar la duda 
Fuera de la "prueba", la palabra del testigo languidece en el mundo de la academia. El testimonio es, a un mismo tiempo, esfuerzo por narrar lo acontecido y margen para el secreto, es aquello que da cuenta sin un tercer testigo que lo legitime y eso mismo que deja algo guardado, lo intestimoniable por indecible. Eso no puede ni quiere hacerlo el conocimiento. Frente al ideal de la transparencia que se sostiene en la generalización de la prueba y en los métodos de verificación y contrastación desarrollados desde tiempos pretéritos por el aparato académico-científico, se levanta otra lógica del discurso, otro modo de la representación: es la voz susurrante y entrecortada, la voz encriptada y secreta del testimoniante, de aquel que no busca una constatación empírica ni intenta despejar, por la vía de lo irrefutable del documento (suponiendo que todavía sigamos instalados en la "ingenuidad objetivista" que vuelve al documento la esencia de la prueba y de lo que debe hacer el historiador serio y confiable) aquello que la memoria y el lenguaje logra apenas rozar. La voz del testigo, esa voz del poema de Celan que sabe de interrupciones, de aliento entrecortado, de desplazamientos y sonidos que se apagan y se deslizan hacia el silencio. Es, por eso, la que hace un juramento que, inmediatamente pronunciado, la instala en una dimensión otra, haciendo de su representación truncada un giro hacia lo sagrado que, en nuestra interpretación, constituye una extraordinaria metáfora de la memoria y sus escansiones, de lo indecible en lo decible, de lo oscuro en la luz, de la ceniza del conocimiento nacida de una muerte intestimoniable.

Apenas el arte poético de un Celan o la escritura cuidadosa y púdica de un Primo Levi, tal vez la cámara que deja que seamos mirados por el horror, de Resnais en Noche y niebla o aquella otra de Lanzmann que muestra sin mostrar, alcancen esa comarca propia del testimonio, aquello que siguiendo a Derrida denominamos $l o$ sagrado. Y el testimoniante, el testigo que intenta pronunciar una palabra, está solo y sin prueba no puede ser autorizado por un tercero o por otro testimonio; esa soledad

respecto de muchas de las 'idées reçues' acerca del Holocausto -lo que podriamos Ilamar la retórica pública o la versión hollywoodense del Holocausto, gran parte de la cual no proviene de los historiadores serios que indagaron sobre ese terrible tema. Y por ende algunos de ellos, como bien sabe cualquier especialista en esta área, tienen una postura de apertura respecto de las criticas". Extraña apertura de los historiadores serios, como los llama Hobsbawm, hacia el ejercicio del revisionismo histórico desarrollado por un connotado representante de la ideología de los verdugos, apertura justificada por el sacrosanto principio de la prueba y la documentación indispensable para aceptar o rechazar un juicio histórico. ¿Desde cuándo un régimen totalitario se ocupa de dejar precisas huellas de sus actos más criminales? o, más directo aun, ¿puede un documento de los genocidas ponerse por encima del testimonio de las víctimas sobrevivientes, alli donde este documento niega completamente lo sostenido por los últimos? Hobsbawm se desliza hacia un terreno peligroso, aquel que, supuestamente justificado por los recursos científicos de la indagación histórica, conduce a la legitimación del revisionismo. 
es, también, la de lo indescriptible, la de quien es testigo sin testigo, la del portador de una soledad sobrecogedora, la de aquel que dando testimonio de lo que aconteció con otro no puede, en verdad, ponerse en el lugar de ese otro, ni siquiera cuando testimonia en favor (Zeugen für jenen).

Escribe Derrida: "Se trata, en otro sentido, de testimoniar por, en el sentido de en lugar de. Nadie puede testimoniar en lugar de otro, así como nadie puede morir en lugar de otro, y en esto vemos la alianza de la muerte y del secreto" (Celan, 1999). Sin embargo, continúa Derrida, el poema de Celan es un poema sobre el testigo, sobre el testimonio, es el entrecortado balbuceo del testigo sobreviviente, su invocación final -Nadie / testimonia / por el testigo- deja al descubierto, si algo queda al descubierto en la escritura enigmática de Celan, la soledad y la presencia, a un mismo tiempo, del testigo, del único que puede pronunciar una palabra que, sin embargo, nadie puede garantizar ni legitimar. Perturbación esencial que recorre el poema, que atraviesa la vida de Celan, que se presenta como recuerdo y dolor inextinguible y que va más allá de toda representación objetivadora, de todo giro de la palabra del testigo a la contrastación de la prueba. Es la alucinación que sufre el testigo ante el juez o el historiador que ponen en entredicho su testimonio porque él precisamente ha sobrevivido. Le damos nuevamente la palabra a Derrida:

El juez, el árbitro, el historiador que recibe y evalúa el testimonio de un sobreviviente de Auschwitz, ya sea que lo acepte o lo recuse: que lo recuse precisamente alegando que, puesto que sobrevivió, el sobreviviente no puede ser un testigo seguro y fiable de lo que sucedió, mucho menos de la existencia para este fin - fin de puesta en muerte - de las cámaras de gas o de los hornos crematorios, y que por tanto no puede testimoniar por los únicos y verdaderos testigos, aquellos que están muertos; tal es así que en este contexto, el poema de Celan puede también resonar como un suspiro desesperado frente a esta situación que permitirá a todos los jueces, árbitros, historiadores considerar a la tesis revisionista como fundamentalmente indestructible (Celan, 1999).

Nódulo esencial que vuelve frágil la palabra del testigo, porque es un testimonio nacido de una interioridad lastimada, de aquel que salió vivo del lugar del que nadie podía ni debía salir vivo. El juez o el historiador escuchan, como testigos, el testimoniar del sobreviviente que les habla de las cámaras de gas y de los hornos crematorios, escuchan palabras pronunciadas en voz baja y desde lo más hondo del dolor que, sin embargo 
y más allá de su buena disposición hacia el testigo, deben ser tomadas con todas las precauciones del caso, buscando contrastarlas con las pruebas fácticas, las únicas que en última instancia podrán garantizar la verosimilitud del relato. La sospecha es un instrumento inherente a la tarea del juez o del historiador, sospecha metodológica, puesta en cuestión de un relato para descubrir sus fisuras, sus exageraciones o sus ocultamientos; el testigo se vuelve sospechoso en el interior de su propio discurso. Comparecer ante el juez para dar su testimonio es, también, ser juzgado, analizado en profundidad, sopesada cada información que brinda, catalogada hasta sus más mínimos detalles. Y el testigo sabe que, en el fondo, su palabra no puede alcanzar la cima de la verdad irrefutable, y que siempre detrás, como un ave de rapiña que espera su oportunidad, se encuentra la terrible sospecha revisionista, aquella que, sobre todo, dirige sus dardos envenenados contra el testimonio del sobreviviente, exigiendo la contrastación fáctica, el reinado omnipresente de la prueba que la voz del testimoniante no puede ni debe ofrecer.

En el límite del testimonio se levanta la impudicia revisionista que, paradójicamente, apela a los consagrados recursos de las ciencias sociales e históricas y que le dice al juez que no debe tomar en cuenta aquello que es del orden de la intimidad, de una interioridad agusanada por la parcialidad, por un equívoco trabajo de la memoria que lo lleva a relatar lo que solo hubiera podido ser narrado por los muertos. Escuchar al testigo, dirá el revisionista, es convocar falsamente a la muerte, es intentar prestarle oídos a lo que no puede hablar. Para el revisionista la verdad está en el documento y la prueba debe ser convocada antes que la voz del testigo. Lo demás es literatura. Perplejidad al descubrir que la argumentación emponzoñada que se dirige a negar el horror del holocausto encuentra su correspondencia en las lógicas académicas, en las teorías de la verdad, en las metodologías imprescindibles que vuelven irrefutable un acontecimiento.

En el artículo de Hobsbawm antes comentado vemos cómo aparece esta argumentación, de qué modo el reclamo de una "emancipación" del historiador de cualquier contaminación ideológica, el abandono de lo que él llama "las deudas con los dogmatismos discursivo-políticos del siglo veinte" se corresponde, en el fondo, con el planteo del historiador nazi Irving, para quien se establece la indulgencia del investigador documentado, del que ha podido acceder a datos fundamentales, frente a una "insignificante" historiadora (Deborah Lipstadt) que supuestamente ha cometido el pecado de la falta de pruebas consistentes que refuercen científicamente su ataque a 
Irving. Estamos, sin duda, ante un debate crucial que atraviesa la problemática de la representación y, en el interior de ella, la estrecha y compleja relación entre memoria, verdad y valores, aquello que en parte Hobsbawm desacredita como "ideologizante", como deudor de las guerras de religión del siglo pasado al que hay que dejar atrás, emancipando al historiador de tales recaídas en la insensatez y la falta de objetividad ${ }^{5}$.

En verdad, el testimonio del testigo debe ser preservado de la mirada ideológica, de ese gesto del discurso político que está más interesado en el enfrentamiento victorioso contra el adversario, que en el imposible decir de quien viene a dar su testimonio. El testigo, Celan en este caso, sabe que su palabra será escuchada desplazándola desde la hondura del dolor que al pronunciarse se vuelve silencio, que regresa de donde vino para instalarse en el lugar sellado desde el comienzo de la pesadilla. Escribe el poeta: "la cicatriz del tiempo / se abre / y cubre la tierra de sangre / los dogos de la noche de palabras, los dogos / ladran ahora / en tus adentros: / festejan la más salvaje sed, / el hambre más salvaje...” (Atardecer de las palabras).

¿Cómo sustraer esa imagen poética, nacida de lo profundo y enigmático, de una memoria acosada por la palabra de los dogos, de una representación ideológica? ¿Es acaso posible aislar el testimonio de lo intestimoniable, la muerte del otro, de las necesidades, muchas veces obscenas, del dispositivo de la transparencia políticojurídica? ¿No sabe el testigo que al testimoniar clausura, en parte, el retorno hacia la intimidad de una memoria que no puede volverse lenguaje y que se guarda en lo más profundo del yo? Y sin embargo, el testigo da su testimonio: “Trasladado al / terreno / del vestigio inequívoco..." (Angostura), allí todo se vuelve intraducible, palabra secreta, intimidad asfixiada, balbuceo del alma que dice más allá de sí misma: "No veían, no, / hablaban de / palabras. Ninguna / se despertó...” (Angostura).

Sin redención, sabiendo que nadie testimonia por el testigo y que es imposible hablar por el otro, $y$, de todos modos, una exigencia indetenible se expresa, busca su salida desde la hondura del yo, subvierte las barreras y no puede sino volverse testimonio.

5 Vale la pena volver a citar a Hobsbawm: "No existe posibilidad alguna de que en cincuenta o incluso cien años la memoria del Holocausto pueda morir, pero esto no se deberá de ninguna manera al caso del que hablé en esta clase. Espero realmente que los historiadores que se topen con el caso 'Irving contra Lipstadt' en sus investigaciones lo consideren como una exposición perteneciente a un museo de antigüedades intelectuales olvidadas desde hace tiempo. Pero para los historiadores de hoy, todavía plantea serios problemas de juicio profesional y moral. Aún nos queda un poco de camino por andar para emanciparnos de la herencia intelectual de la era de las guerras de religión que dominó el siglo XX. Tal vez debamos hacer el intento de acelerar nuestra emancipación". 
¿Cómo franquear la distancia que separa la voz del testigo de aquellas otras formas de la representación? ¿Es también la voz del testigo una forma de la representación? ¿Es el poema un límite, el umbral de un precipicio que no se puede sortear cuando se va en pos de la memoria de los muertos, cuando se intenta hacer cristalizar aquello que asoló la vida? Celan (1999) nos contesta:

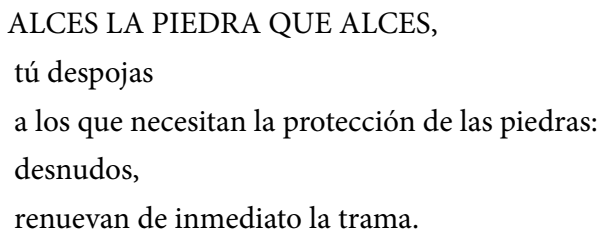

Así como la reflexión que Derrida intentó tejer alrededor del testigo que testifica no alcanza a sustraerse a la prohibición que subyace a no hablar por el otro, especialmente cuando ese otro ha muerto, el poeta vuelve sobre una palabra truncada, irredenta, que allí donde regresa sobre los que han sido despojados y permanecen desnudos renueva, sin quererlo y sin impedirlo, la trama de la perdición. Celan nos lo dice, se lo dice dolorosamente a sí mismo, que sus palabras, aquellas que se vuelven poema y que retornan sobre las heridas de la memoria, son, también, cómplices en el juego de la representación de lo irrepresentable, insistencia por citar lo que, al volver, no se libera de la pesadilla ni del sufrimiento sino que, en ese regresar, certifica su continuada muerte. Quizás lo que Celan nos está queriendo decir es que el arte, en este caso la representación poética, no debe concluir en catarsis, no debe permitirle a la conciencia de nuestro tiempo un giro estetizante hacia la época de la humillación de 
la vida. Pero también nos está planteando el problema esencial de una representación que no clausure aquello que permanece irredento, que no se vuelva alivio de una conciencia que es capaz de procesar lo improcesable, alejándolo de su propia experiencia, colocándolo en el territorio del arte, de un lenguaje compensador y consolador.

Ese lenguaje que busca el camino de la representación, que se desespera por hallar un resquicio desde el cual poder decir algo que no se vuelva perdición, que no regrese hacia los muertos con la forma de la impudicia catártica, de aquellos lenguajes del arte que solo sirven para desplazar y petrificar, en el pasado acontecido y sellado, lo terrible de ser mostrado; ese lenguaje, el de Paul Celan, sabe del umbral infranqueable, sabe de los límites del sentido y de la caída en el balbuceo:

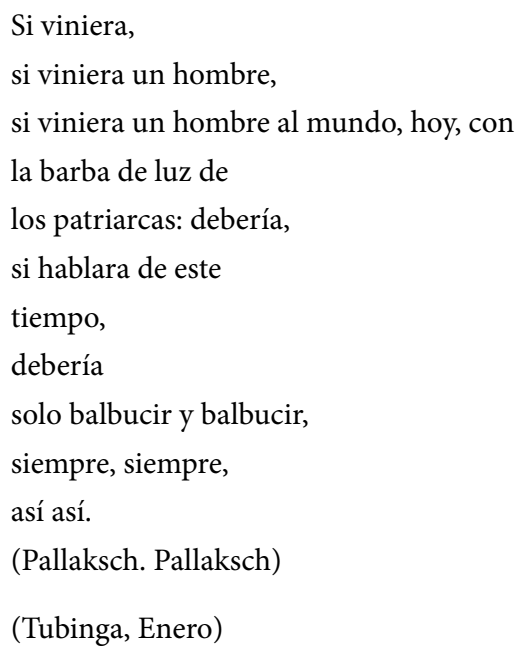

¿Puede el arte balbucir y solo balbucir? ¿Puede detenerse allí donde el silencio es lo único que dice lo indecible? ¿Es acaso posible exigirle a la representación estética que traicione su naturaleza? ¿Debe el arte, cualquiera sea este, callar o detenerse ante el misterio de la muerte? Celan escribe un poema que se entrama con aquella famosa sentencia adorniana en la que se señalaba la imposibilidad de seguir escribiendo poesía después de Auschwitz. ¿Quién, de dónde, cómo puede escapar al balbuceo nacido de una época impiadosa? Ese hombre, con la barba de luz de los patriarcas, también debería, afirma el poeta, al hablar de este tiempo maldito "solo balbucir y balbucir". Ni aquel que es portador de las promesas del cielo, el que lleva el mensaje de la luz, puede sustraerse a la prohibición, a la tragedia de un habla que al pronunciarse 
vuelve a caer en la maldición. No era algo distinto lo que intentaba decir Adorno, y no es diferente la travesía poética de Celan, una travesía que se hace en el interior de esa imposibilidad, de esa prohibición que, aparte de rodear lo monstruoso, busca preservar la memoria de los muertos. En un poema dedicado a Nelly Sachs, Celan volvió sobre esa palabra callada:

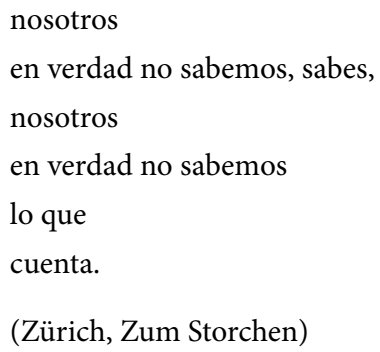

El poema no elude la representación, no lo puede hacer, pero lo que sí elude es un modo hegemónico de la representación que tuvo su origen en el tallado moderno del sujeto de conocimiento; ese modo supuso una correspondencia entre el lenguaje y el mundo, un plegamiento, mejor dicho, del mundo a las exigencias normativas del lenguaje. La representación como producción intensiva de objetividad, de mundos en perspectiva que debían su sentido, en última instancia, a la posicionalidad representadora del habla conceptual del sujeto. Más allá de la crisis que desde Mallarmé en adelante destituyó el contrato entre palabra y mundo, aquello que verdaderamente inauguró el tiempo del no saber y del no poder decir, fue Auschwitz. Punto límite, silencio del verbo ante la barbarie absoluta que, con la prolijidad de un relojero maldito, desplegó las fuerzas destructivas desde el seno de esa misma lógica de la representación que había echado las bases, en el origen de la modernidad y de su sujeto, de la vía regia de la objetualización de seres humanos y naturaleza.

Auschwitz hace estallar el sentido, no porque este no se haya cumplido en los campos de la muerte, sino precisamente porque el itinerario histórico de la razón moderna no pudo impedir que desde su propio seno emergieran las fuerzas destructivas de lo humano, haciendo del lenguaje del sujeto cómplice de la maldad radical. Adorno, y también Celan, se mueven en el interior de la onda expansiva de una barbarie que dejó al habla racional no solo sin argumentos emancipatorios sino, más grave aún, la comprometió con la barbarie. Toda la poesía de Celan es un denodado esfuerzo, que lo lleva al umbral infranqueable de lo que las palabras pueden decir, por intentar 
suspender la representación en el interior de un ámbito trabajado por las metáforas, las elipsis, los balbuceos, los silencios, las sugerencias interrumpidas, las referencias que huyen de la univalencia interpretativa, el pudor infinito ante la muerte intestimoniable. En "Argumentum e silentio" el poeta se confronta con esos límites:

A cada uno la palabra.

A cada uno la palabra que le cantó, cuando la jauría le atacó por la espalda.

A cada uno la palabra que le cantó y quedó helada.

A ella, a la noche,

lo sobrevolado de estrellas, lo sobrebañado de mar,

a ella lo logrado al silencio,

cuya sangre no cristalizó cuando el colmillo del veneno traspasó las sílabas.

A ella la palabra lograda al silencio.

Contra las otras que pronto,

prostituidas por las orejas de los desolladores, también trepan por el tiempo y los tiempos, testimonia por último, por último, cuando solo cadenas resuenan, testimonia por la que allí yace entre oro y olvido, hermanas de ambos de siempre.

¿Pues dónde alborea, di, sino en ella, que en la cuenca de su río de lágrimas a los soles sumergiéndose la semilla muestra una y otra vez? (Argumentum e Silentio) 
"Cuya sangre no cristalizó cuando el colmillo del veneno / traspasó las sílabas", compromiso del lenguaje con aquello que haría imposible la continuidad de la vida; señalamiento de la caída que sobrepasa a aquella otra caída nacida del pecado de Adán y Eva. Sin embargo, el poeta no quiere ni puede renunciar en la batalla por preservar la memoria "contra las otras que pronto, / prostituidas por las orejas de los desolladores, / también trepan por el tiempo y los tiempos...", y amenazan con doblegar el decir humano, volviéndolo solo hacia la muerte y la maldición; es allí cuando es necesario que la palabra se vuelva testimonio: "testimonia por último, / por último, cuando solo cadenas resuenan, testimonia por la que allí yace / entre oro y olvido, / hermana de ambos de siempre". ¿Quiebra Celan la prohibición de que alguien testimonie por el testigo? Dar su testimonio como obligación de la memoria de quien "yace / entre oro y olvido" no significa ponerse en el lugar del otro ni tampoco representar lo irrepresentable; supone, apenas, el intento de proteger con palabras lo que está amenazado desde múltiples lados: por la muerte intestimoniable, por el relato de los vencedores y, también, por la impudicia representativa de un arte que ha olvidado los límites que no se deben traspasar.

El mismo nombre del poema, "Argumentum e Silentio", destaca la permanencia de la tensión, el peligro de todo rebasamiento pero la presencia, como un centinela, del silencio. Y el final, independientemente de cualquier otra interpretación posible y hasta contradictoria con lo que vamos a decir, quizás, y utilizamos el quizás para eludir cualquier tentación afirmativa, sugiera que solo a través de la palabra de cada uno, que debe ser rescatada del olvido, sea factible un giro más allá de su envenenamiento, “ipues dónde / alborea, di, sino en ella, / que en la cuenca de su río de lágrimas / a los soles sumergiéndose la semilla muestra / una y otra vez?”. ¿Acaso sea ese el único lugar de la esperanza? ¿El río de lágrimas en el que se sumerge la semilla de la vida? Celan, en el sinuoso camino de su poética, insiste en el entrelazamiento de peligro y oportunidad, de catástrofe y esperanza, aunque, casi en un giro benjaminiano, sepa que el fluir de la historia conduce prioritariamente hacia la continuidad del desastre y la oscuridad más que a la plenitud redencional.

Tal vez podamos inferir en la escritura concentrada y abierta del poeta judeorrumano los trazos de un posible derrotero del pensamiento de Benjamin si este hubiera sobrevivido a la guerra. Tal vez, e intentamos ser muy cuidadosos con las palabras y las suposiciones, Celan haya sobreimpreso su poesía en las Tesis de filosofía de la historia, le haya señalado, allí donde Benjamin todavía esperaba la presencia, aunque 
tenue y débil, de lo mesiánico, la postergación, una vez más, de la promesa. Sin Gracia y en medio del silencio de una muerte irredenta, el testimonio del autor de Fuga de muerte apenas si puede sostener la imagen de ese débil hilo que desde la lejanía de los tiempos sigue habitando la esperanza judía. En un poema de Cambio de aliento leemos:

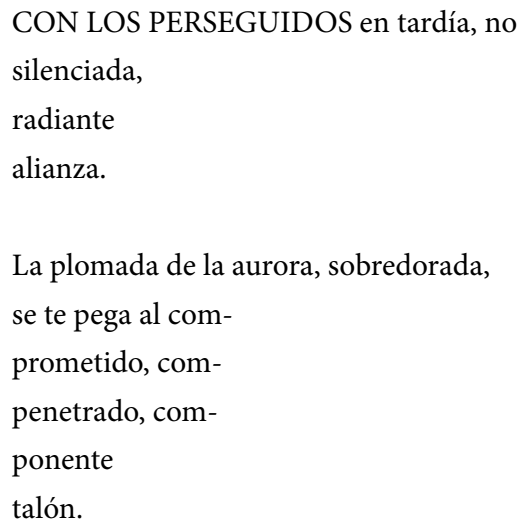

"La plomada de la aurora" nos sugiere que la esperanza lejos de alcanzar el cielo de la promesa, se vuelve hacia lo hondo, se sumerge en aguas turbias y, como el talón de Aquiles, muestra toda su debilidad, el punto por el que la muerte puede enseñorearse. El abismo de la aurora, la hondura que tanto atrajera a Celan, el hundimiento de lo que se espera, la catástrofe en el tiempo.

\section{Referencias}

Celan, P. (1999). Obras completas. Madrid: Trotta.

Derrida, J. (1996). Hablar por el otro. Diario de Poesía, 39.

Hobsbawm, E. (2000). Cuando la política ciega a los historiadores. El Clarín, suplemento Zona.

Steiner, G. (1987). La longue vie de la métaphore. L’Écrit du Temps, 14-15. Paris: Minuit. 